\title{
Design Elements for a CSCL Environment in a Teacher Training Programme
}

\author{
Ditte Lockhorst ${ }^{1}$, Wilfried Admiraal ${ }^{1}$, Albert Pilot ${ }^{1}$ and Wim Veen ${ }^{2}$ \\ 1) Institute of Education, Utrecht University, PO Box 80127, 3508 TC Utrecht, The Netherlands \\ d.lockhorst@ivlos.uu.nl \\ 2) Faculty of Technology, Policy and Managment, Delft University of Technology, Jaffalaan 5, \\ 2628 BX Delft, The Netherlands
}

Keywords: collaborative learning, electronic communication, teacher education, didactics, research

\begin{abstract}
In the design of a Telematic Learning Environment (TLE) in which student teachers learn collaboratively, we consider three clusters of design elements as important: the Telematic Work Environment, the guidance of the instructor and the task instruction. We will have a look at the way group and task behaviour, triggered by these design elements influence the collaborative outcomes. Experiments have revealed that the technical environment is not as important as we had expected beforehand. This research shows that the task instruction (pre-imposed structure, role taking and intrinsic motivation for the task) and the group process itself have far more impact on the online collaborative work of the student teachers.
\end{abstract}

\section{INTRODUCTION}

Computer Supported Collaborative Learning (CSCL) is receiving considerable attention in contemporary educational research. (Kagan 1994) stresses the need for co-operative learning because "increasingly, the workplace consists of interdependent teams working on complex problems 
which no individual alone can solve" (p. 2:1). In addition, both schools and universities show a growing attention for co-operative learning and the use of new media and Telematic environments.

The purpose of our study was to examine the elements involved in designing a training environment in which student teachers effectively learn to cooperate by means of Telematics. In this paper, we will describe these design elements and emphasise the task instruction, based on a literature study and expert interviews (Lockhorst 1999). In addition, we will also discuss the student teachers' evaluation of their co-operative processes in two studies involving different Telematic Learning Environments (TLE's).

These studies have taken place in the framework of our larger research project at IVLOS, the Institute of Education of the Utrecht University in the Netherlands, in which different TLE's have been designed, implemented and evaluated. The first study described in this paper was our first TLE, which we based on a preliminary theoretical orientation. The second TLE we will discuss was based on the results of the first study.

\section{CSCL AND THE DESIGN OF TLE'S}

Studies show that it is difficult in TLE's to have a meaningful discussion showing elaboration, explanation, and reciprocal exchange. In fact, sometimes there is no discussion at all.

There are several variations on the group- and task arrangements that influence the interaction in a group and that are relevant to our study. Positive interdependence, which can be reached by goal- and resource interdependence, can stimulate effective group behaviour (Johnson and Johnson, 1994). We assume that individual accountability, in many cases translated in reward interdependence (e.g. Johnson and Johnson 1994), is an important factor for creating effective groups, but we are sceptical about the use of rewards in adult education. Another way to create individual accountability could be the evaluation of the individual's role during the process (Strom and Strom 1996). According to Cohen (1994), interdependency should be fostered by presenting challenging tasks and stimulating learner's intrinsic motivation and collaborative skills.

The task arrangement influences the interaction as well. Cohen (1994) states that a strong structuring of the work process hampers the collaborative process, particularly when adult learners are presented with ill-structured problems. The use of roles is questionable, as studies disagree on the effect of role taking on the interaction.

The number of participants in a group and their background (ability, race, gender, age, etc.) influence the co-operative learning process as well. Groups 
of four seem to diminish the chance of the free-rider or sucker effect (Cohen 1994). Groups with learners who have different frames of reference can stimulate the discussion and the exchange of information, as the group members are mutually dependent with regards to information resources and skills. Miller and Harrington (1992) indicate personalisation as an important factor for working efficiently, as it overrides participants' initial categorisation and leads to shared responsibility. The experts interviewed have indicated that, in an on-line environment, personalisation is even more important and preferably done in face-to-face (F2F) meetings.

On the basis of expert interviews and the literature search on CSCL and TLE's in general, we distinguish three clusters of design elements: the Telematic work environment, the task instruction and the teachers' guidance. In addition, the context, including the student characteristics as well as all preconditions of the educational context in which the students and teachers worked (such as the technical conditions of the students at home), also play an important role. The design cluster 'Telematic work environment' refers to the functionalities of the website and programme used, the navigation and the structure. With the 'task instruction' we mean characteristics of the task, such as role taking, pre-imposed structure, task specialisation, type of task, and the training of students. It relates to the instruction the students receive before the co-operative task begins. The 'teachers educators' guidance' refers to the teachers' instruction and communication during the on-line task.

\section{RESEARCH METHOD}

In both studies, data was gathered through individual and group interviews with student teachers and teacher educators, semi-structured questionnaires for student teachers, electronic logfiles, and the storage of electronic communication of all groups.

The results of the two studies described here are based on an analysis of the student teachers' questionnaires and the electronic communications. Social Network Analysis (SNA) has been used to quantify and visualise the amount and type of interactions.

The pre-structured questions were measured on a 5-point Likert scale. The response rate was $100 \%$. Descriptive statistics will be presented and student response to the essay questions are summarised and included in the results. In the presentation we will focus on the task instruction. In our studies, we observed that this aspect had more influence on collaboration than both the teachers' guidance or the features of the Telematic work environment. 


\section{STUDY 1: HISTORY TEACHING METHODS}

\subsection{Design of TLE}

The first study to be described is a teacher-training course on history teaching methods, attended by 15 student teachers and run in the second half of 1999. Objectives of the course were to increase students' knowledge and experience with teaching methods, with the use of ICT and with co-operative learning. The students worked on four on-line assignments in groups of three to four using the TLE for communication and document exchange. The students worked in heterogeneous groups based on training background (fulltime, in-service, international students) aiming that students could take advantage of each others' knowledge and experiences because of the various frames of reference of the group participants. In this way we tried to stimulate reciprocal interdependence. The students had a F2F meeting every other week at the institute in which they presented their group outcomes and talked about additional assignments. They did not receive any grades for their assignment, but had to include the end products and a reflection on the collaboration process in their portfolios. The students received a low preimposed structure of the task: they had to plan the assignment and divide the tasks among themselves on-line. Only manuals with directions for group behaviour were provided on-line.

The TLE included information about the course, manuals on how to work with Internet, groupware and directions co-operative learning, a diary inlcuding all deadlines and milestones, hyperlinks to educational resources, the assignments and an expert (experienced history teacher educator) for feedback on individual teaching experiences and group assignments. Groupware was attached to the TLE. Bscw (http://bscw.gmd.de) as workspace for the groupwork, and Webboard (http://webboard.com) as social platform. The students received a training on how to use the website and exchange messages and files during the first face-to-face meeting.

Group 1

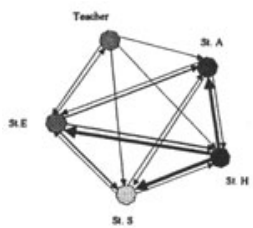

Group 2

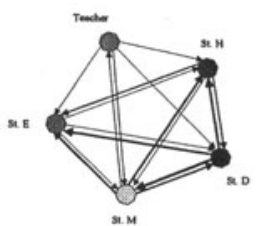

Group 3

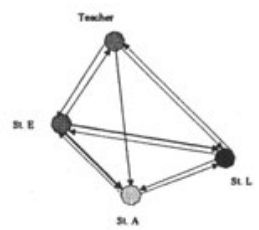

Group 4

Figure 1. Interaction patterns of 4 groups 


\subsection{Results}

Figures 1 shows the interactions patterns of the four heterogeneous groups. The thickness of the arrows represent the amount of messages sent.

In three groups, the frequency of communication was low, while in group two the frequency of communication was relatively high and equally divided. A satisfying co-operative learning process should have been one where students participated equally and actively by reading and commenting on the work of group mates while also contributing their own work. On the whole, there was little on-line discussion as the students tended to go over to task specialisation. Individual contributions were compiled at the end without further consideration. Most communication referred to organisational and procedural matters and document exchange.

Although the groups did not work as was planned, the students experienced positive outcomes. Twelve students indicated that their knowledge of the use of ICT had increased and that they have learned to cooperate with their peers. Fifty percent of the students thought the on-line work had helped them to increase their knowledge of subject teaching methods. However, almost all students felt that they would have increased their knowledge more if the assignments had been done F2F. Striking is the fact that the students did not appreciate the social function of the TLE. From many other studies (e.g. McIntyre and Tlusty 1995) we know that most student teachers experience the social function (exchange of experiences, emotional and motivational support) as an important outcome. Social contact in our TLE was less important to the students because they did not know each other very well, and because they already had social contact in other training groups.

Although the students found the groupware to be complex, they thought the programme was fairly easy to use. However, problems with Internet connections or the absence of a computer at home delayed work and demotivated the students.

\subsubsection{Task instruction}

Several aspects of the task instruction may have had a restrictive influence on the on-line discussion. Firstly, most students found the heterogeneous groups to be unpleasant. Differences between the types of students were more profound then expected and the students were not open to feedback from other types of students. Only the students of group two were positive about the mixed group composition and this helped their discussion to be productive. 
Secondly, the groups experienced low personalisation. The students did not know each other beforehand and although team building was a focus during the first F2F meetings, this was only done in the whole group and not in the subgroups of four. This resulted in the students' lack of responsibility for the group work and negative personal relationships.

A third reason could be the fact that the students were not motivated for the assignments. In spite of the use of ill-structured problems, the students thought the assignments were not challenging enough as they focussed on theoretical rather than practical topics. In addition, some students indicated that the structure of the assignments triggered task specialisation. This task specialisation, combined with the lack of criticism from the teachers on the incoherent end products, resulted in limited on-line discussions. The use of a portfolio as a single assessment tool does not seem to encourage students to discuss the content on-line.

Finally, the time period in which the students had to work on the assignments was too short ( 2 to 4 weeks). Setting up a lively discussion takes more time, especially when some students only have access to an online connection once a week.

The lack of on-line discussion about the content led the teachers to give the groups time during the F2F meetings to plan their work at the start of each assignment period. Together with an interim evaluation, this stimulated the team feeling. The agreements made on planning and procedures in the F2F setting stimulated students' responsibility towards the group assignments.

\section{STUDY 2: INTERNATIONAL TEACHER EDUCATION PROGRAMME}

\subsection{Design of TLE}

This study was implemented in the first half of 2000 as part of IVLOS's international teacher training programme. Seventeen Dutch students, located all over the world, participated during their overseas teaching practice period. Objectives of this TLE were to train the students in teaching strategies, to continue units of study that started at the institute, to guide the students while they were abroad, and to keep the students in contact with each other and the training institute. The students worked, in different groups on four on-line assignments, which were running parallel during a period of four months. One of these (called TIE) was the focus of the second study. Its 
design was based on the results of the first experiment on history teaching methods. The students had to design, revise and actually give a lesson in a second-language class with the help of their group mates. In this study, we decide to use a pre-imposed structure; in contrast to the first study which was marked by a limited on-line discussion, task specialisation and the assembly of individual end-products. The groups received a week to week prescribing procedure, specifying who had to do what aspect of the task and when. In addition, the roles were strictly defined: each role and its corresponding task was described in detail.

The second TLE differed on other aspects of the design. There were no F2F meetings, the guidance of the students was completely on-line except for one visit of a teacher per country and the groups consisted of three students, located in different countries. Another difference with the first experiment is the groupware used. Because the communication in Bscw quickly becomes unorganised, we decided to use Webct (http://www.webct.com/wyw) in this study.

\section{$5.2 \quad$ Results}

The logfiles of WebCT show that the students have used the website intensively, particularly the Bulletin Board. Again the functionality and usability of the groupware was not a restrictive factor. WebCT generated no problems.

Figure 2 shows the amount of messages read and posted by the students. The social discussion forum in particular was used frequently and very long discussion threads were produced. The students made it very clear that they appreciated the social function of the TLE: it kept the group together. This is

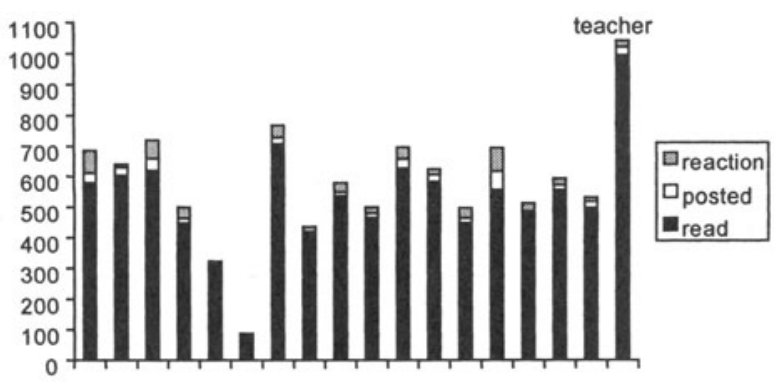

Figure 2. Number of messages read and written 
not surprising, because the group knew each other very well before their work in the TLE and they were physically separated for some month's.

Figure 3 shows the interaction patterns of two of the TIE groups, which are representative for all TIE groups. The figures show that there was an equal interaction pattern, implying that the three group members were involved in the on-line discussion with the same frequency.

Group 1

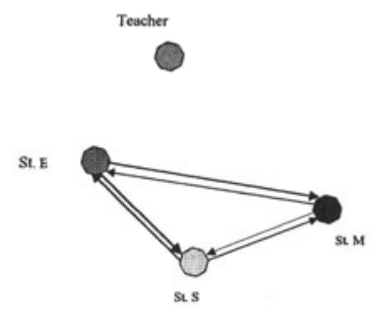

Group 2

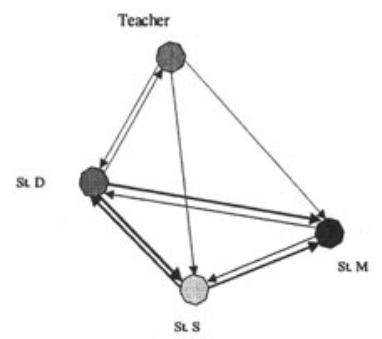

Figure 3. Interaction patterns of two TIE groups

\subsubsection{Task instruction}

Most groups did work out the assignment on a satisfactory level. However, the majority of students felt that the TIE assignment was useless $(94.1 \%)$. They used terms like: artificial, time-consuming, not related to the things they were doing, did not see the goal. Their motivation to do the assignment was very low, and they felt working on it as an obligation. The absence of assessment and feedback from the teacher educator increased their feelings of uselessness of the assignment. However, the pre-imposed structure and role taking offered them a framework to work in. A similar result has been found in another of our experiments, in which students did little work on the assignment for the first three months until the teacher gave them a very strict pre-imposed structure, after which all the work was completed in just one month (Lockhorst 2000).

The students did not like the TIE assignment, and did it perfunctorily, contrary to other assignments in this TLE, in which they had to make their own planning and procedures. Three groups used the TLE voluntarily to complete one of these assignments. Notable is that in their discussion forums the largest amount of messages were exchanged. The students clearly saw the usefulness of the TLE for their co-operation and this resulted in an extensive discussion and information exchange. This shows that intrinsic 
motivation is important in on-line co-operative learning. Nevertheless, when students have to complete assignments for which they are less motivated, a pre-imposed structure and role taking could help them to carry out the assignment (extrinsic motivation).

\section{CONCLUSION AND DISCUSSION}

Three clusters of design elements have been presented. The results of the two studies described implicate that the influence, of these clusters on the group and task behaviour, differ.

Both studies show the importance of the task instruction. The impact of the use of a pre-imposed structure, role taking and intrinsic motivation has been substantial in both studies. In the first study, a minimal pre-imposed structure and lack of motivation for the task resulted in very limited on-line discussion and co-operation. The second study shows that, although students were not motivated for the assignment, the pre-imposed structure and role taking stimulated them to co-operate on the task. In our opinion there is much attention in the field of CSCL for outcomes and the cognitive learning process, while less attention is paid to the influence of the task instruction. This seems strange in some sense, because in research on co-operative learning, the importance of task instruction is recognised.

The fact that the students of the second study knew each other very well and had no F2F contact, motivated them to work on-line. In contrast, the students of the first experiment mentioned that lack of personalisation, the atmosphere in the groups, the lack of shared interests, concerns and feelings of responsibility for the group as well as the product, had a negative effect on their group behaviour. The heterogeneous grouping on the basis of training background thus frustrated the co-operative learning process. In future research on CSCL, more attention should be paid to the group process (including student characteristics) and the influence of this on the outcomes.

Both studies do reveal that the technical environment did not have a great impact on the outcomes. We used different groupware and although there were some dissimilarities in user-friendless and functionalities, the programmes were useful for the tasks. The technical context of the students at home and their technical skills did have a great impact on their role in the group process. Cautiously, we dare to say that, considering its limited impact, the technical environment should not receive so much attention in CSCL research. Many researchers work on the development of new programmes for CSCL, with special and more and more advanced functionalities. This is undoubtedly useful, but to study the influence of these new programmes on the outcome of CSCL without considering the influence 
of the task instruction, the teachers' role and group dynamics, is not doing justice to the latter.

\section{REFERENCES}

Cohen, E. G. (1994) Restructuring the Classroom: Conditions for Productive Small Groups.

Review of Educational Research, 64 (1), pp. 1-35.

Johnson, D. W. and Johnson, R. T. (1994) Learning Together. In Handbook of Co-operative learning methods, S. Sharan (ed.), CT: Greenwood press, Westport, pp. 51-65.

Kagan, S. (1994) Co-operative Learning. Moore Data management services, San Diego.

Lockhorst, D. (1999) Summary of the interviews. Internal report. IVLOS/Utrecht University, Utrecht, The Netherlands.

Lockhorst, D. (2000) Evaluatie Teleleren ICLON: project Vuistregels. (Evaluation Telelearning at ICLON: project Rules of Thumb) IVLOS/Utrecht University, Utrecht, The Netherlands.

McIntyre, S. R. and Tlusty, R. H. (1995) Computer-mediated discourse: electronic dialogue journaling and reflective practice. Paper presented at the AERA, San Fransisco.

Miller, N. and Harrington, H. J. (1992) Social categorization and intergroup acceptance:

Principles for the design and development of cooperative learning teams. In Interaction in cooperative groups, the theoretical anatomy of group learning, $\mathbf{R}$. Hertz-Lazarowitz and N. Miller (eds.), Cambridge University Press, Cambridge, pp. 203-225.

Strom, R. and Strom, P. (1996) Student Evaluation of Social Skills. Journal of Instructional Psychlogy, 23 (2), pp. 111-117.

\section{BIOGRAPHY}

Ditte Lockhorst has worked for more than ten years as a consultant on ICT in education. From multi-media developer, she co-ordinated of the EU REFLECT project and also worked in the EU T3 Project (Telematics for Teacher Training). Wilfried Admiraal is educational researcher. His research is focused on how to include peer students into university teaching and learning in order trigger effective and efficient learning processes, with or without the use of electronic learning environments. Albert Pilot is full professor of curriculum development in IVLOS Institute of Education at Utrecht University an in 1998 also as professor of Chemistry Education in the Department of Chemistry of that university. Wim Veen is head of the Centre of Educational Innovation and Technology at Delft University of Technology. This centre provides training and consultancy services for educational change and curriculum development for faculties, professional development of university teachers, and teacher training for secondary education. 